\title{
Análise hierárquica da qualificação de Operadores Logísticos (OL): uma visão conceitual baseada no método AHP
}

\author{
Diogo Barbosa de Queiroz \\ Centro Universitário Augusto Motta \\ Av. Paris, 84 - Bonsucesso, Rio de Janeiro \\ Diogo.engpro@yahoo.com \\ Valéria Pereira Ramos \\ Centro Universitário Augusto Motta \\ Av. Paris, 84 - Bonsucesso, Rio de Janeiro \\ valeria.vrpereira@gmail.com \\ Marcos dos Santos \\ Instituto Militar de Engenharia (IME) \\ Praça Gen. Tibúrcio, 80 - Urca, Rio de Janeiro \\ marcosdossantos_doutorado_uff@yahoo.com.br
}

\begin{abstract}
RESUMO
Esse trabalho objetiva aplicar o método de Análise Hierárquica do Processo (AHP), para apoiar empresas na seleção de um Operador Logístico. Um operador logístico é uma empresa prestadora de serviços, responsável pelo gerenciamento e execução de atividades logísticas, ou seja, uma empresa terceirizada que fornece serviços de transporte de produtos, administração, mão de obra, gestão de estoques, entre outros, para uma empresa contratante. O Método de Análise Hierárquica do Processo, utiliza-se de técnicas de modelagem e simulação matemática a fim de se dar suporte nas tomadas de decisão que envolva subjetividade e/ou informações que não são totalmente quantificáveis, estruturando critérios, atribuindo valores e selecionando alternativas. Com a utilização desse método espera-se qualificar o Operador Logístico e encontrar a melhor decisão a ser tomada para que satisfaça as necessidades da empresa, visando uma melhor otimização dos recursos, beneficiando a empresa como um todo e com isso entregar um produto final que satisfaça as necessidades do cliente.
\end{abstract}

Palavra-chave: Operador logístico, Análise Hierárquica do Processo.

\begin{abstract}
These paper objectives apply the Hierarchical Process Analysis (HPA) method to support companies in selecting a Logistics Operator. A logistics operator is a service company, responsible for the management and execution of logistics activities, ie a third party that provides product transportation, administration, labor, inventory management services, among others, to a contracting company. . The Hierarchical Process Analysis Method uses mathematical modeling and simulation techniques to support decision making involving subjectivity and / or information that is not fully quantifiable, structuring criteria, assigning values and selecting alternatives. By using this method it is expected to qualify the Logistics Operator and find the best decision to be made to satisfy the company's needs, aiming at a better optimization of resources, benefiting the company as a whole and thereby delivering a final product that satisfy customer needs.
\end{abstract}


Keywords: Logistics Operator, Hierarchical Process Analysis.

\section{Como Citar:}

QUEIROZ, Diogo Barbosa de; RAMOS, Valéria Pereira; SANTOS, Marcos dos. Análise hierárquica da qualificação de Operadores Logísticos (OL): uma visão conceitual baseada no método AHP. In: SIMPÓSIO DE PESQUISA OPERACIONAL E LOGÍSTICA DA MARINHA, 19., 2019, Rio de Janeiro, RJ. Anais [...]. Rio de Janeiro: Centro de Análises de Sistemas Navais, 2019.

\section{INTRODUÇÃ̃O}

No passado, mais precisamente nos anos 1970, os pontos de produção e de consumo tinham que estar próximos entre si, pois a logística como nós conhecemos hoje em dia não funcionava de forma eficiente e informatizada e as empresas não consideravam a logística como parte da estratégia. Basicamente não existia uma cadeia de suprimentos e gerenciamento logístico sobre a mesma, se limitando apenas como uma atividade de transporte entre fornecedor, fabricante e comércio varejista.

Conforme a evolução da globalização, a logística tomou grandes proporções nos últimos anos, novas técnicas e métodos foram aprimorados para aperfeiçoar as atividades das empresas, logo para aumentar o lucro. A administração como área principal se dividiu em diversas disciplinas, uma foi à logística, a qual desempenha funções essenciais para competitividade que o mercado exige nos tempos modernos.

A logística trata do planejamento, execução e controle de mercadorias, serviços, transporte, gestão de estoque relativo ao produto desde o seu ponto de origem como matéria prima até o produto como forma de consumo, em regra, de modo eficiente. A partir do momento em que o mercado e seus agentes econômicos ficaram mais exigentes, a logística se tornou mais dinâmica e complexa. As empresas perceberam a necessidade de aumentar a qualidade de seus produtos, logo, precisaram aprimorar seus processos produtivos aumentando assim seus custos operacionais. Por conta disso viu-se a necessidade de terceirizar suas atividades logísticas, a fim de reduzir os custos e priorizar a sua atividade principal, e assim surgiu a terceirização da logística, que se tornou uma importante estratégia das organizações, pois se por um lado às empresas que visão o lucro no geral, a logística se preocupa em reduzir custos, o que acarreta no aumento do lucro.

Com base no exposto acima, os Operadores Logísticos (OL) atuam como as empresas que tem o objetivo de fazer a cadeia de suprimentos ${ }^{1}$ da empresa funcionar da melhor maneira. Os Operadores são empresas que fornecem serviços de logística para terceiros contratantes de forma personalizada. A terceirização da logística pode ocorrer em empresas de diversos tamanhos, mas a necessidade maior costuma a surgir quando a empresa é maior.

\footnotetext{
${ }^{1}$ Rede interligada de atividades e processos, que abrange desde o armazenamento da matéria-prima até o produto final no ponto de consumo. (BALLOU, 2006)
} 
OL são empresas especialistas e possuem know how para gerenciar uma cadeia de suprimentos e suas atividades logísticas. Vale ressaltar que a terceirização das atividades logísticas não extingue o planejamento estratégico da empresa contratante do serviço em relação às atividades de logísticas dentro da cadeia de suprimentos. Assim, percebe-se a importância de se contratar um OL que satisfaça as necessidades da empresa, a ferramenta AHP apoiará nessa tomada de decisão. Os principais motivos e benéficos para terceirizar essas atividades estão representados na Figura 1.

Figura 1: Motivos mais frequentes que justificam a terceirização da logística

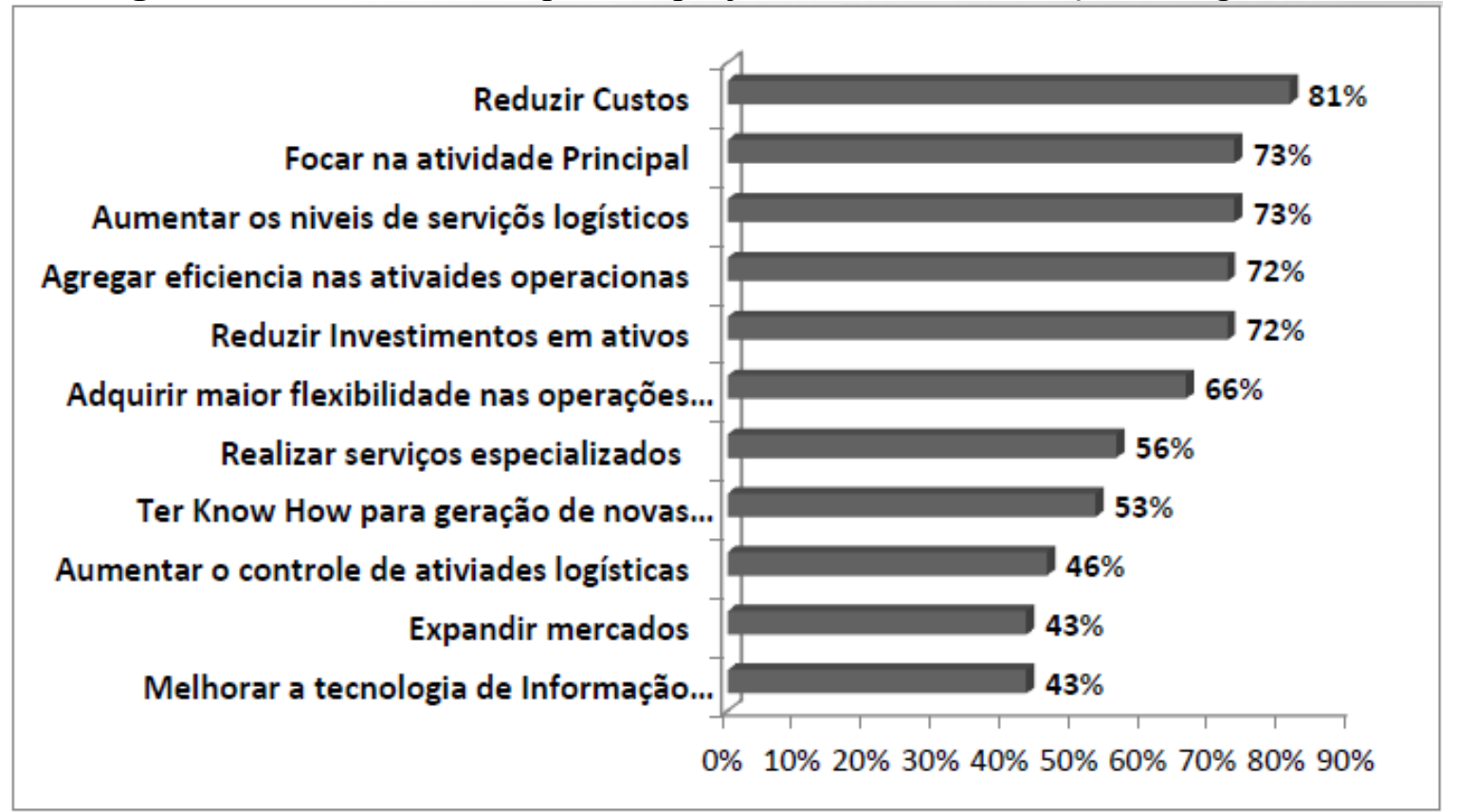

Fonte: Adaptado de Panorama terceirização logística 2011 - COPPEAD

O AHP é um método utilizado para dar apoio a tomadas de decisão, principalmente em decisões que são complexas, com poucas informações quantitativas e que depende da analise de pessoas, logo, se torna subjetiva. Esse método de modelagem matemática foi desenvolvido em meados da década de 1970, pelo pesquisador americano Thomas L. Saaty, quando se começava a abordar problemas complexos sob a visão de critérios simultâneos e de análise qualitativa. Não havia, na época, muitas abordagens desse tipo. Os pilares básicos que tornam o AHP um método respeitado nas organizações, se deve ao seu pioneirismo, a partir da globalização mundial. A sua simplicidade de entender e de aplicar, estruturando critérios, estabelecendo valores de julgamento e selecionando alternativas.

A estratégia da empresa contratante de um OL, juntamente com seus gestores, será de estruturar os critérios convenientes para selecionar a empresa prestadora de serviços (OL), estabelecendo valores de julgamento para cada critério, em relação a outro sob análise, não se limitando a todos e por fim selecionar a melhor alternativa.

\subsection{Objetivo}

O objetivo deste artigo é propor a utilização do método AHP para apoiar uma tomada de decisão de uma empresa em contratar um prestador de serviços logístico ou Operadores 
logísticos. Deixar evidente a importância de um OL, seus benefícios e vantagens nas organizações. Junto ao crescimento tecnológico, com a contratação de Operadores logísticos com especialistas, as empresas poderão gerenciar elos da cadeia de suprimentos dentro de uma visão global, e aperfeiçoar diversas atividades logísticas.

Os motivos apresentados não representam as necessidades e pontos fracos de todas as empresas. $\mathrm{O}$ uso estratégico de OL é diferente para cada tipo de empresa e também não estingue as empresas de riscos futuros. Nosso foco estratégico será definido em critérios préestabelecidos e homologados como de suma importância para a seleção e contratação destes OL.

\section{REVISÃO E LITERATURA}

\subsection{Logística}

Há milhares de anos, já se encontravam métodos logísticos utilizados pelos povos em diversas atividades. Um exemplo disso são as pirâmides do antigo Egito, sem uma organização e transporte organizado em fases, aqueles monumentos nunca teriam sido construídos. Guerras foram vencidas pelos esforços dos logísticos (CHRISTOPHER, 2007).

A segunda guerra mundial (1939-1944) alavancou pesquisas cientificas, métodos de trabalho e impulsionaram as organizações ao redor do mundo a utilizarem tais descobertas e avanços, isso não foi diferente com a logística. Os líderes militares utilizavam a logística para a definição de pontos de guerra, por estas serem longas e longes era necessário traçar pontos estratégicos e planejamento, analisado os melhores locais de combate e através do desenvolvimento comercial das cidades notou-se a inevitabilidade de existir pontos de produção e de consumo que tinham que estar próximos entre si (CHRISTOPHER, 2007).

Após a guerra, as atividades logísticas começaram a ser utilizadas pelas organizações, a fim de se ganhar tempo com transporte de matérias, logo otimizando os processos e cortando custos, essa era a premissa básica. A logística das empresas, até os anos 1950, era direcionada apenas as atividades de transporte e armazenagem. Nas décadas seguintes essa limitação da logística começa a mudar, as empresas começaram a perceber importância da distribuição física dos produtos. Mas, é somente após a década de 1990 que a logística começa a acumular novas funções, incorporando novos métodos, profissionais e outras atividades, se tornando algo muito maior do que era na década de 1950. (ROCHA, 2007).

Hoje em dia, a logística está mais desenvolvida para a formação de estratégias nas empresas, ela se transformou em um diferencial competitivo, num mercado tão disputado. Como o conceito de logística é amplo, a definição de Ronald Ballou (1993) explica bem o conceito de logística. Para ele

"Logística é o processo de planejamento do fluxo de materiais, objetivando a entrega das necessidades na qualidade desejada no 
tempo certo, otimizando recursos e aumentando a qualidade nos serviços."

A Logística empresarial se desenvolveu da importância da redução de custos nas empresas e na maior relevância que se dá hoje em atendimento das necessidades dos clientes. Quando todos os produtos se tornam iguais, a empresa mais competitiva será aquela que conseguir ser mais eficiente e eficaz, se antecipando a prováveis problemas que possam vir a ocorrer (BALLOU, 2006).

\subsection{Operador Logístico}

Muitas pessoas ao ouvirem a expressão "operador logístico", logo pensão que isso significa um cargo ou uma profissão. Isso é equivocado, pois na verdade, um OL é uma empresa que presta serviços logísticos para terceiros. É uma empresa contratada por outra para fornecer serviços de administração, tecnologia da informação e mão de obra logística, com o objetivo de reduzir custos e agregar qualidade nos processos de cadeia de suprimentos, logo para agregar qualidade no produto que passa por essa cadeia de suprimentos (BERTAGLIA, 2009).

As empresas terceirizam as suas operações logísticas por vários motivos. Um dos principias motivos é a busca pela primarização ${ }^{2}$ das principias atividades da empresa. Isso não significa que as atividades logísticas não sejam importantes para a empresa, pelo contrario, nos dias atuais, com um mercado tão competitivo, a logística se tornou um diferencial, fazendo parte do planejamento estratégico das organizações.

Estrategicamente, empresas que gerenciam seus fluxos de bens, serviços, finanças e informações dentro de uma cadeia integrada de forma competente, com diversos agentes, como: fabricantes, fornecedores e varejistas, agregam valor competitivo junto ao mercado consumidor. Isso pode ser feito com excelência através de uma empresa especialista, como os OL. Além da empresa que contrata um OL, com o objetivo de focar na sua atividade principal, fatores como, redução de custos, desburocratização de leis trabalhistas e aperfeiçoamento de processos, aparecem como outros motivadores da contratação desses especialistas em operações logísticas. (BERTAGLIA, 2009).

Existem diversos tipos de OL, a contração desses serviços pode ser flexível de acordo com a necessidade da empresa contratante. Podemos categorizar operadores logísticos como:

- OL comuns: que são aqueles que prestam o serviço de logística mais "básica" por assim dizer gerenciam o armazém onde serão estocados os produtos e também o transporte e embalagem dos produtos.

\footnotetext{
${ }^{2}$ A primarização dos serviços ou mão de obra é a qualificação dada à inversão do processo de terceirização. Este conceito surgiu no início do século XXI como vertente contrária aos efeitos negativos da terceirização. (PORTER, 2007).
} 
- OL com foco na administração: são aqueles que não têm como foco realizar a armazenagem em si, e sim prestar serviços de consultoria logística, fornecer recursos mão de obra especializada e também sistemas de gerenciamento de estoque.

- OL híbridos: que são aqueles que fornecem todo o processo logístico, desde o planejamento, a armazenagem e a mão de obra e a execução de todas as áreas logísticas, esse tem como característica assumir a logística da empresa como um todo, tendo autonomia em tomadas de decisões estratégicas para esse fim.

\subsection{Cadeia de Suprimentos}

O objetivo do Gerenciamento da Cadeia de Suprimentos (GCS) é conseguir eficácia e eficiência nos processos em relação aos principais indicadores, como Lead Time ${ }^{3}$, por exemplo, e ter uma sinergia das partes da cadeia produtiva até a criação do valor dos produtos ao cliente final, obtendo um controle de informações e recursos colhidos, visando sempre melhorias além de estratégias que venham a focar na satisfação, prospecção e retenção dos clientes, acabando com a visão antiga de apenas vender e entregar, (SIMCHI-LEVI, D.; KAMINSKY, 2003)

Visto isso, a condução de uma boa gestão da cadeia de suprimento em sintonia com a visão sistêmica da logística é onde, na maioria das vezes, as empresas procuram seu ponto de melhoria e desempenho com foco ao agregar valor dos seus produtos e serviços e Christopher (1999) aponta que somente num passado recente é que as organizações empresariais reconheceram o impacto vital que o gerenciamento logístico pode ter na obtenção da vantagem competitiva.

As organizações buscam por vantagens competitivas através da integração de seus processos com fornecedores e clientes, em função da necessidade de se ajustarem às mudanças ocorridas no ambiente interno e externo. Neste sentido, a integração passa a ser uma das palavras chave na obtenção de vantagens competitivas, no momento em que as exigências são excessivamente grandes no ponto de vista de uma empresa isolada, propiciando uma maior ênfase das cadeias de suprimentos (HARRISON E HOEK, 2003).

\subsection{Método Análise Hierárquica}

O Método de Análise Hierárquica é um método utilizado para estruturar multicritérios de qualificação, a fim de apoiar tomadas de decisão com subjetividade de escolha. Foi introduzido pela primeira vez por Saaty em 1971 para resolver a alocação de recursos escassos no planejamento militar. Desde sua introdução, o AHP tornou-se um dos métodos multicritério de apoio em tomadas de decisão largamente utilizado nas organizações e por qualquer um que deseja estruturar um processo de tomada de decisão.

${ }^{3}$ Lead Time é uma medida do tempo necessário para um produto ou serviço percorrer todas as etapas do processo de uma cadeia de suprimentos, do início até o fim, (HARRISON e HOEK, 2003). 
A premissa básica do AHP é que um problema decisório que possui alta subjetividade de escolha de soluções pode ser estruturado de maneira hierárquica, onde o topo da hierarquia contém a sua descrição geral e nos níveis mais abaixo estão os critérios que são levados em consideração para a abordagem. Para resolver problemas em diferentes áreas tais como avaliação e seleção de fornecedores, recrutamento e seleção de candidatos a cargos nas organizações, priorização de projetos para alocação de recursos, seleção de sistemas de TI, escolha do melhor local para construção de uma fábrica e decisões militares sobre a construção ou não de sistemas de defesa. Além de reduzir a subjetividade das decisões, o método permite, em alguns casos, a redução na duração do processo (ALMEIDA e MURAKAMI, 2005).

\section{METODOLOGIA}

Metodologia utilizada para a elaboração desse trabalho se caracteriza como uma pesquisa exploratória de cunho qualitativo, ao passo que os problemas relacionados a serem solucionados pelo que o artigo propõe não são possíveis de serem quantificados. Portanto este trabalho irá apresentar métodos e teorias com base em analises qualitativas.

\subsection{Principais desafios de Gerenciamento da Cadeia de Suprimentos}

Com base em análises qualitativas e pesquisas exploratórias, constatou-se que os principais desafios a serem superados de forma competente com um bom serviço prestado por um OL passam por alguns problemas recorrentes dentro dos processos, planejamento, abastecimento, produção, distribuição e/ou devolução, este ultimo considerando logística reversa, (COELHO, 2010).

Integração da GCS: Fazer um gerenciamento de excelência da logística na empresa é um elemento essencial para o sucesso. Mas os problemas surgem e é preciso saber gerencialos para superar as adversidades e obter resultados satisfatórios. Para isso, é preciso conhecer exatamente quais são os obstáculos que podem aparecer dentro dos processos e das redes de empresas que formão a cadeia logística, conforme ilustrado na Figura 2.

Figura 2: representação de uma cadeia de suprimentos e seus elos

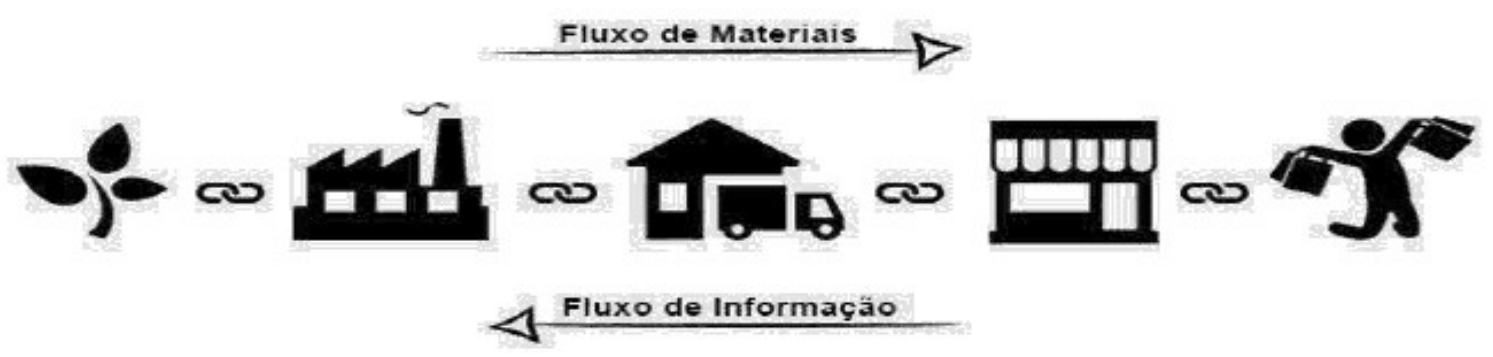

Fonte: Adaptado de BALLOU (2006)

\subsection{Critérios de escolha para qualificar os operadores Logísticos}


Os critérios foram escolhidos empiricamente pelos autores, com base nas experiências adquiridas tanto na formação acadêmica como na atuação profissional industrial. A metodologia do AHP é que um problema de tomada de decisão pode ser estruturado de maneira hierárquica em relação aos critérios definidos. É importante ressaltar que um os critérios são passiveis de subjetividade de escolha. Empresas possuem diferentes estruturas, atividades econômicas, tamanhos, portanto os critérios escolhidos como relevantes para esse trabalho representam um todo, mas não estão limitados a apenas esses critérios.

\subsubsection{Contrato com base no desempenho}

Um critério bastante relevante na hora de qualificar um OL é a elaboração de contratos baseados no desempenho. Esses são comuns no setor, e pré acordam a remuneração do OL com base na medição de indicadores previamente estabelecidos, como por exemplo, Lead time de entrega, perda ou extravio de mercadorias, entre outros Feedback ${ }^{4}$ do usuário. A vantagem deste tipo de contrato é que tanto o operador logístico quanto a empresa operam em prol de ganhos mútuos, favorecendo a prestação de um bom serviço.

\subsubsection{Abrangência geográfica}

É importante que a empresa contratada possua alcance logístico de transporte que satisfaça a distribuição em regiões onde os clientes e fornecedores estão localizados. Possuir armazéns em locais estratégicos pode ser um diferencial que aumente abrangência geográfica.

\subsubsection{Flexibilidade}

A escolha de um bom fornecedor passa pela flexibilidade. Os fornecedores devem se mostrar flexíveis para se adaptarem às mudanças constantes do mercado. Na logística, muitas vezes o OL precisa se adequar rapidamente às certas necessidades do cliente, por isso é necessário ter flexibilidade sem abrir mão da organização e da qualidade do serviço.

\subsubsection{Mão de Obra capacitada}

Os profissionais que atuam na logística devem possuir o conhecimento e a experiência necessária para prestar um bom serviço. Tanto para mão de obra operacional, como exemplo: motoristas, despachantes. Como a nível administrativo e gerencial, para agregar visão de planejamento estratégico, gerência de estoques, de custos tempo etc. A empresa terceirizada devo buscar os melhores profissionais no mercado, a contratação de candidatos depende do grau de formação, do tempo de experiência nas funções logísticas e também do perfil dos candidatos, não se limitando apenas a esses fatores.

\footnotetext{
${ }^{4} \mathrm{O}$ significado de feedback no ambiente empresarial refere-se a avaliação que é dada a um grupo, um processo ou colaborador individualmente, sobre ações ou resultados obtidos.
} 


\subsubsection{Custo benefício}

Um dos critérios mais relevantes em relação à escolha do OL diz respeito a custos. Por isso, a empresa deve estar atenta se o fornecedor é capaz de oferecer serviços a preços competitivos e compatíveis com o mercado. Como a empresa já tem como premissa uma economia inicial, decorrente da própria terceirização, vale pesquisar bastante sobre o custo benefício de cada serviço oferecido pelo OL.

\subsubsection{Capacidade de transporte e armazenagem}

É fundamental para um OL oferecer a capacidade de transporte, armazenamento e gerenciamento necessária, com objetivo de as necessidades e manter o fluxo na GCS. Para isso, tecnologias e ferramentas de rastreamento de veículos, sistemas de roteirização, auditoria de fretes, tecnologia de rádio frequência, código de barras etc., devem ser utilizadas pelo OL.

\subsubsection{Sistema de Informação}

A tecnologia da informação como estratégia de redução de custos, permiti um aperfeiçoamento do serviço na melhoria das atividades logísticas dentro da empresa, construindo uma maior vantagem competitiva. Como a logística concentra-se do fluxo de bens ao longo do canal de distribuição, à tecnologia na área da logística deve contar com sistemas que funcionam como elo entre as áreas de uma empresa e também dos membros do canal de suprimentos visando à adequação da necessidade do cliente em ter o produto que escolheu correto desde o pedido realizado até o tempo e local de entrega correto. Estes sistemas são de grande importância para o mercado consumidor, trazendo para a logística a necessidade de trabalhar de maneira eficiente e eficaz. Sendo assim, existem disponíveis no mercado vários sistemas de informação para apoiar as operações logísticas, como o ERP.

\subsection{Aplicação dos critérios no método AHP}

A partir dos critérios predefinidos eles serão submetidos por um julgamento de valor, em uma escala determinada que levará a análise qualitativa dos critérios e a subjetividade da tomada de decisão a três possíveis cenários a serem analisados de maneira quantitativa. Para as alternativas dos OL a serem escolhidos, serão utilizados os pseudônimos $\mathbf{x}, \mathbf{y}$ e z, logo, três (3) alternativas.

\subsubsection{Julgamentos de Valor (escala de conversão)}

Para a comparação paritária entre as alternativas, utilizou-se a Escala Fundamental de Saaty, apresentada na Tabela 1.

Tabela 1: Escala Fundamental de Saaty 


\begin{tabular}{lc}
\hline \multicolumn{2}{c}{ Preferência / Importância } \\
\hline Igual & 1 (um) \\
Moderada & 3 (três) \\
Forte & 5 (cinco) \\
Muito Forte & 7 (sete) \\
Absoluta & 9 (nove) \\
Intermediários & $2,4,6,8$ \\
\hline
\end{tabular}

Fonte: Adaptado de Saaty (1980)

\subsubsection{Estruturação da Hierarquia}

Figura 3: Estrutura da AHP

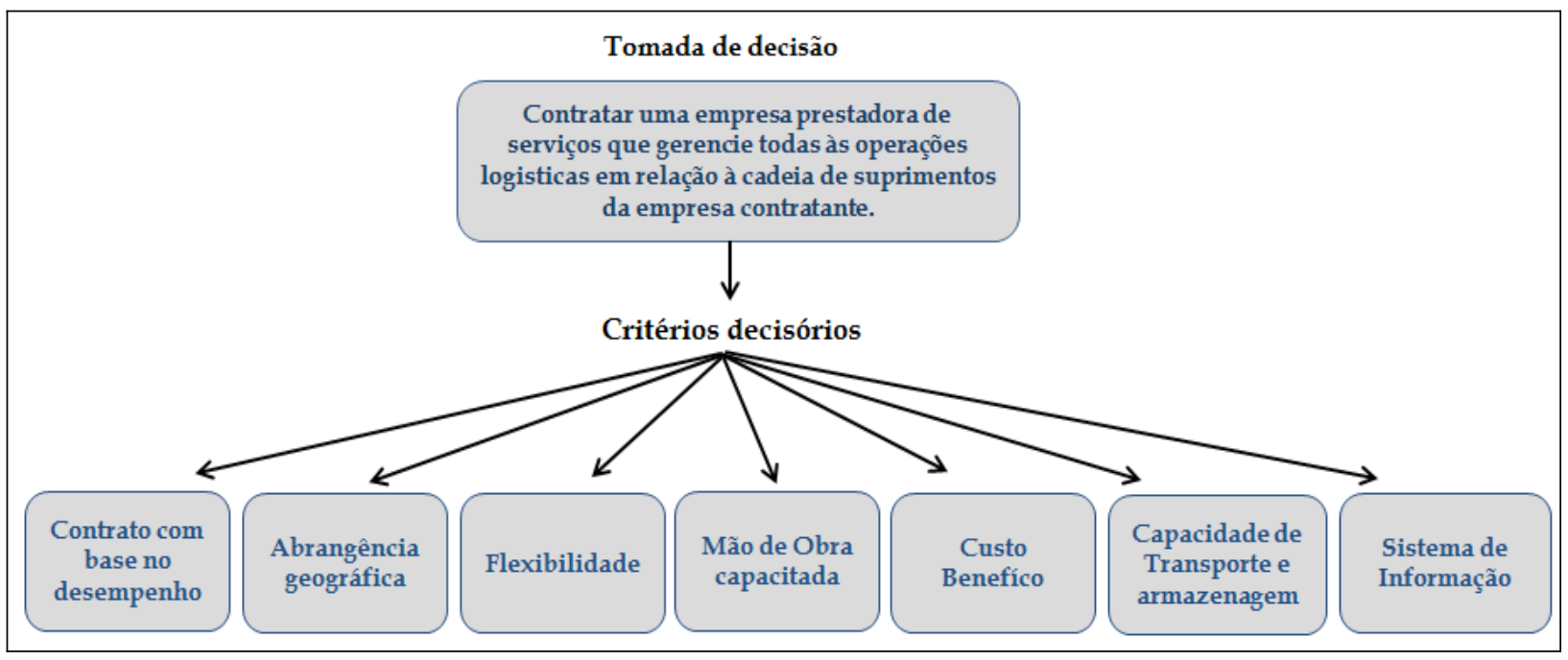

Fonte: Autores (2019)

\subsubsection{Procedimento}

Após a estruturação do modelo hierárquico e da definição dos julgamentos de valor quantitativo, a etapa seguinte contempla cinco passos sequencias até a obtenção do resultado ideal:

1) Montar os quadros de julgamento;

2) Normalizar os quadros de julgamentos;

3) Fazer o cálculo de prioridade média relativa;

4) Fazer o cálculo de prioridade média absoluta e

5) Realizar a análise da consistência. 
1) Montar os quadros de julgamentos

Conforme o Critério: Contrato com base no desempenho. Três alternativas: $\mathbf{x}, \mathbf{y} \mathbf{e} \mathbf{z}$

- X possui uma atuação moderada em relação a $Z$

- Y possui uma atuação forte em relação $Z$

- Y possui uma atuação entre igual e moderada em relação a X

A modelagem matemática começa a ser representada ns Tabela 2.

Tabela 2: Comparação paritária para o critério desempenho

\begin{tabular}{|c|c|c|c|}
\hline $\begin{array}{c}\text { Contrato com base } \\
\text { no desempenho }\end{array}$ & $X$ & $Y$ & $Z$ \\
\hline$X$ & $\mathbf{1}$ & 0,5 & $\mathbf{3}$ \\
\hline$Y$ & $\mathbf{2}$ & $\mathbf{1}$ & $\mathbf{5}$ \\
\hline$Z$ & 0,333 & 0,2 & $\mathbf{1}$ \\
\hline
\end{tabular}

Fonte: Autores (2019)

Os julgamentos definidos são convertidos para quadros de julgamentos com o auxílio da Escala Fundamental de Saaty. O mesmo procedimento deve ser realizado para todos os critérios.

2) Normalizar os quadros de julgamentos

Após a definição dos valores para cada critério em relação às alternativas. A etapa 2 consiste em fazer o cálculo da soma dos elementos de cada coluna do quadro de julgamentos e depois fazer a divisão de todos os elementos de cada coluna do quadro de julgamentos, pelo somatório referente à coluna. Segue como exemplo o mesmo quadro da etapa anterior.

Figura 4: Processo de normalização 


\begin{tabular}{|c|c|c|c|}
\hline $\begin{array}{c}\text { Contrato com base } \\
\text { no desempenho }\end{array}$ & $X$ & $Y$ & $Z$ \\
\hline$X$ & $\mathbf{1}$ & 0,5 & $\mathbf{3}$ \\
\hline$Y$ & $\mathbf{2}$ & $\mathbf{1}$ & $\mathbf{5}$ \\
\hline $\mathrm{Z}$ & 0,333 & 0,2 & $\mathbf{1}$ \\
\hline SOMA & $\mathbf{3 , 3 3 3}$ & $\mathbf{1 , 7}$ & $\mathbf{9}$ \\
\hline
\end{tabular}

\section{Quadros Normalizado}

\begin{tabular}{|c|c|c|c|}
\hline $\begin{array}{c}\text { Contrato com base } \\
\text { no desempenho }\end{array}$ & $X$ & $Y$ & $Z$ \\
\hline$X$ & $\mathbf{0 , 3 0 0}$ & $\mathbf{0 , 2 9 4}$ & $\mathbf{0 , 3 3 3}$ \\
\hline$Y$ & $\mathbf{0 , 6 0 0}$ & $\mathbf{0 , 5 8 8}$ & $\mathbf{0 , 5 5 5}$ \\
\hline$Z$ & $\mathbf{0 , 0 9 9}$ & $\mathbf{0 , 1 1 7}$ & $\mathbf{0 , 1 1 1}$ \\
\hline
\end{tabular}

Fonte: Autores (2019)

É importante ressaltar que após a normalização de cada campo, a soma dos valores nas colunas deve ser $1+-0,1$, ou seja: $0,999<1<1,001$.

3) Fazer o cálculo de prioridade média relativa (PMR)

As Prioridades Médias Relativas (PMR) são obtidas para cada um dos julgamentos ou quadros normalizados. Elas são as médias das linhas dos quadros normalizados.

Tabela 3: Prioridades médias relativas

\begin{tabular}{|c|c|c|c|c|}
\hline $\begin{array}{c}\text { Contrato com base } \\
\text { no desempenho }\end{array}$ & $X$ & $Y$ & $Z$ & PMR \\
\hline$X$ & $\mathbf{0 , 3 0 0}$ & $\mathbf{0 , 2 9 4}$ & $\mathbf{0 , 3 3 3}$ & $(0,3+0,294+0,333) / 3=\mathbf{0 , 3 0 9}$ \\
\hline$Y$ & $\mathbf{0 , 6 0 0}$ & $\mathbf{0 , 5 8 8}$ & $\mathbf{0 , 5 5 5}$ & $(0,6+0,588,+0,555) / 3=\mathbf{0 , 5 8 1}$ \\
\hline$Z$ & $\mathbf{0 , 0 9 9}$ & $\mathbf{0 , 1 1 7}$ & $\mathbf{0 , 1 1 1}$ & $(0,099+0,117+0,111) / 3=\mathbf{0 , 1 0 9}$ \\
\hline \multicolumn{5}{|c}{ Fonte: Autores $(2019)$} \\
\hline
\end{tabular}

A PMR para o critério "contrato com base no desempenho" é 0,309, 0581 e 0,109. Isto significa que a empresa $\mathrm{X}$ tem prioridade de $\mathbf{3 0 , 9 \%}$ de ser escolha, a empresa $\mathrm{Y}$ tem $\mathbf{5 8 , 1 \%}$ e a empresa $Z$ tem $\mathbf{1 0 , 9 \%}$. Esses valores estão relacionados apenas a um critério, se apenas esse critério fosse relevante, a empresa Y seria o OL contratado. O calculo de PMR deve ser feito para todos os critérios e também para a tomada de decisão principal.

4) Fazer o cálculo de Prioridade Média Absoluta (PMA)

As PMA identificam as prioridades em cada julgamento. Para calcular a PA é necessário combinar as PMR em um vetor de Prioridades Absoluto (PA), conforme indicado na Tabela 4. 
Tabela 4: PMR das alternativas $\mathrm{X}, \mathrm{Y}$ e $\mathrm{Z}$

\begin{tabular}{|l|c|}
\hline \multicolumn{1}{|c|}{ Tomada de decisão/ Critérios } & PMR \\
\hline Selecionar um OL & Y Z \\
\hline Contrato com base no desempenho & 0,$309 ; 0,581 ; 0,110$ \\
\hline Abrangência geográfica & 0,$377 ; 0,151 ; 0,472$ \\
\hline Flexibilidade & 0,$539 ; 0,297 ; 0,164$ \\
\hline Mão de Obra Capacitada & 0,$546 ; 0,084 ; 0,370$ \\
\hline Custo Benefício & 0,$211 ; 0,241 ; 0,549$ \\
\hline Capacidade de Transporte e Armazenagem & 0,$201 ; 0,681 ; 0,118$ \\
\hline Sistema de Informação & 0,$185 ; 0,082 ; 0,088 ; 0,127 ; 0,375 ; 0,065 ; 0,078$ \\
\hline Selecionar um OL & \\
\hline
\end{tabular}

Fonte: Autores (2019)

Para encontrar a Prioridade Absoluta (PA) de cada alternativa, faça o somatório do produto de cada critério da PMR do foco principal pelo PML de cada alternativa à luz do respectivo critério. Conforme apresentado na Figura 5.

Figura 5: Cálculo da PA de cada alternativa

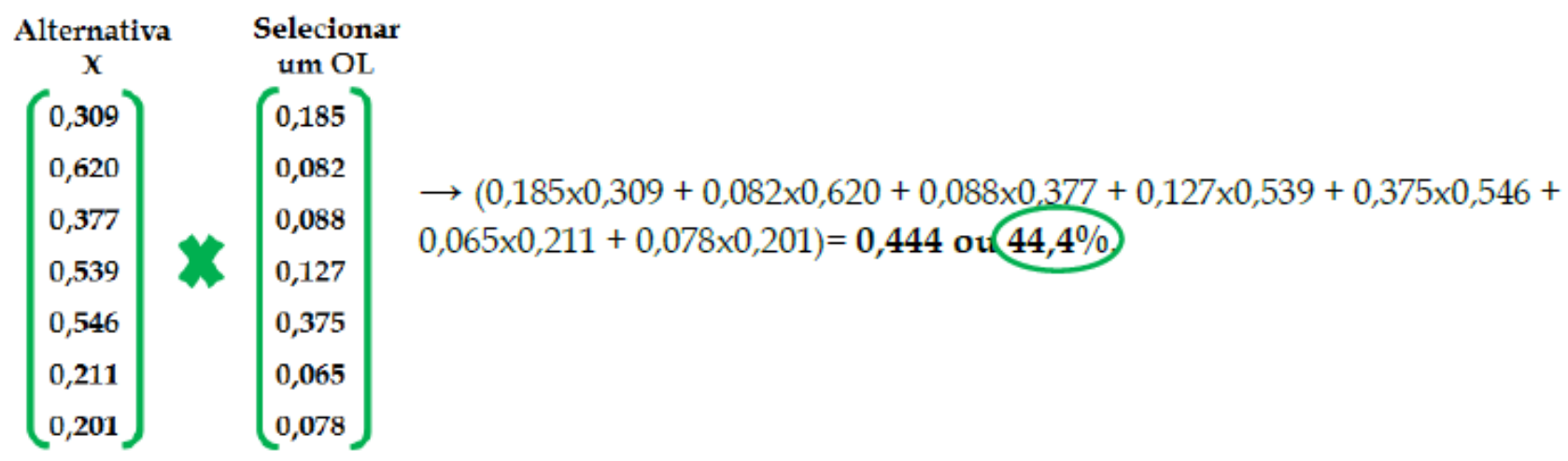

Fonte: Autores (2019)

Fazendo o cálculo de PA para as alternativas Y e Z, obtemos respectivamente $27 \%$ e $29 \%$. Então conclui-se que as prioridades médias globais são:

- $44 \%$ é a prioridade OL X para ser selecionado;

- $27 \%$ é a prioridade do OL Y para ser selecionado e

- $29 \%$ é a prioridade do OL Z para ser selecionado. 
Sendo assim, após as quatro etapas de processos de modelagem e estruturação do método AHP, a melhor alternativa para se tomar a decisão de contratar o operador logístico é a empresa $X$.

5) Análise da consistência

A próxima e ultima etapa é calcular a Razão de Consistência (RC) para aferir o quanto os julgamentos foram consistentes em relação aos valores completamente aleatórios. Se o RC é superior a 0,1 os julgamentos não são fidedignos, porque estão imoderados perto para o conforto de aleatoriedade, neste caso os resultados obtidos não apresentam valores consistentes. Para calcular a RC é necessário primeiro obter o valor de $\lambda$ que representa $o$ maior autovalor da matriz $\mathrm{A}$, obtido a partir da seguinte equação: $\mathrm{IC}=\left(\lambda_{\max }-\mathrm{N}\right) / \mathrm{N}-1$

Onde $\mathrm{N}$ e $\lambda \max$ representam a ordem e o autovalor da matriz de julgamentos. $\mathrm{O}$ cálculo de autovalores segue uma série de procedimentos e operações algébricas com matrizes. Para exemplificar essa etapa continua-se a utilizar o critério com os resultados das etapas anteriores.

Tabela 5: Ponderações, valores normalizados e PMR do critério "contrato com base no desempenho".

\begin{tabular}{|c|c|c|c|c|c|c|c|}
\hline $\begin{array}{c}\text { Contrato com base no } \\
\text { desempenho }\end{array}$ & $\mathrm{X}$ & $\mathrm{Y}$ & $\mathrm{Z}$ & \multicolumn{3}{|c|}{ Valores Normalizados } & PMR \\
\hline $\mathrm{X}$ & $\mathbf{1}$ & 0,5 & $\mathbf{3}$ & $\mathbf{0 , 3 0 0}$ & $\mathbf{0 , 2 9 4}$ & $\mathbf{0 , 3 3 3}$ & $\mathbf{0 , 3 0 9}$ \\
\hline $\mathrm{Y}$ & $\mathbf{2}$ & $\mathbf{1}$ & $\mathbf{5}$ & $\mathbf{0 , 6 0 0}$ & $\mathbf{0 , 5 8 8}$ & $\mathbf{0 , 5 5 6}$ & $\mathbf{0 , 5 8 1}$ \\
\hline $\mathrm{Z}$ & 0,333 & 0,2 & $\mathbf{1}$ & $\mathbf{0 , 1 0 0}$ & $\mathbf{0 , 1 1 8}$ & $\mathbf{0 , 1 1 1}$ & $\mathbf{0 , 1 1 0}$ \\
\hline SOMA & 3,333 & $\mathbf{1 , 7}$ & 9 & \multicolumn{3}{|c}{} &
\end{tabular}

Fonte: Autores (2019)

Considerando-se os valores referentes à primeira etapa do processo de ponderação (não os valores normalizados) como uma matriz A de ordem $3 \times 3$ e os valores de PMR como um auto vetor $\alpha$, onde $A \alpha=\lambda \alpha$ e $\alpha \neq 0$. Tem-se: Cálculo de $\lambda_{\max } \rightarrow \lambda=A \alpha / \alpha$

$$
\left(\begin{array}{ccc}
1 & 0,5 & 3 \\
2 & 1 & 5 \\
0,33 & 0,2 & 1
\end{array}\right) \times\left(\begin{array}{c}
\alpha \\
0,309 \\
0,581 \\
0,110
\end{array}\right)
$$

O resultado do produto da matriz A com o vetor $\alpha$ encontra-se na coluna Vetor A $\alpha$ da Tabela 6 , juntamente com a resolução completa do cálculo de $\lambda_{\max }$. 
Tabela 6: Resultados do produto da matriz A com o vetor $\alpha$

\begin{tabular}{|c|c|c|c|c|c|}
\hline \multicolumn{3}{|c|}{ A } & q & Vetor Aq & $\mathrm{A} \alpha / \alpha$ \\
\hline 1 & 0,5 & 3 & 0,309 & 0,928 & 3,00 \\
\hline 2 & 1 & 5 & 0,581 & 1,747 & 3,01 \\
\hline 0,33 & 0,2 & 1 & 0,110 & 0,329 & 3,00 \\
\hline
\end{tabular}

Fonte: Autores (2019)

Logo, o valor do $\lambda_{\max }$ é o maior valor do vetor, que corresponde a 3,01. Aplicando esse valor na fórmula de $\mathrm{RC}$ e caso este valor seja maior do que $\mathbf{0 , 1}$ recomenda-se a reformulação do modelo e/ou a revisão dos julgamentos. O Índice de consistência IR é um valor tabulado pré-definido por Saaty (1980). Esse índice é obtido por uma matriz recíproca, com valores não negativos e obtidos de forma aleatória. Também conhecidos por índices randômicos ${ }^{5}$. Os valores randômicos são escolhidos em função da ordem da matriz, toda via, para uma matriz $3 \times 3$ o $I R=0,58$. Segue a fórmula de $I C$ e $R C$ a partir dos valores encontrados: $I C=(\lambda \max -N) / N-1 \rightarrow(3,01-3) / 3-1=0,005 ; R C=I C / I R \rightarrow 0,005 / 0,58=0,008$

A consistência do julgamento para o critério "contrato com base no desempenho" é válida, pois o $\mathrm{RC}$ é menor que $0,1(0,008 \leq 1)$. O mesmo procedimento deve ser realizado para todos os critérios.

\section{Resumo do procedimento:}

- Identificar $\mathrm{RC}$ a partir de $R C=I C / I R$

- IR pode ser encontrado a partir da tabela de valores randômicos proposta por Saaty.

- IC pode ser encontrado pela formula $\mathrm{IC}=(\lambda \max -\mathrm{N}) / \mathrm{N}-1$

\section{CONCLUSÃO}

Os ganhos com redução de subjetividade de escolha em se utilizar o AHP são importantes para apoiar uma tomada de decisão complexa. A facilidade de uso e de compreensão da ferramenta por todos, faz com que todos os interessados entendam o problema da mesma forma e assim permite-se visualizar o inter-relacionamento entre os fatores. Este trabalho apresentou como a ferramenta AHP pode ser aplica para apoiar uma tomada decisão de qualificação e contratação de um operador logístico, ao passo que essa decisão envolve multicritérios, assim como outros diversos tipos de tomadas de decisão que estão presentes no mundo coorporativo.

\footnotetext{
${ }^{5}$ São números onde não possuem uma medida definida, que postos em sequencia não dá pra definir com exatidão o próximo da sequencia, (SAATY, 1980)
} 


\section{REFERÊNCIAS BIBLIOGRÁFICAS}

ALMEIDA, M. I. R.; MURAKAMI, M. Abordagem Estratégica de Tomada de Decisão Baseada no Método AHP (Analytic Hierarchy Process). In: XVIII Congresso Latino Americano de Estratégia, 2005, Santa Cruz de la Sierra. SLADE, 2005.

BALLOU, Ronald H. Logística empresarial: transportes, administração de materiais e distribuição física. São Paulo: Atlas, 1993.

BALLOU, Ronald H. Autor 1. Gerenciamento da Cadeia de Suprimentos: Logística Empresarial. 5. ed. Edição Brasil: Local de publicação ARTMED, Editora 2006.

BertagliA, P. R. Logística e Gerenciamento da Cadeia de Abastecimento. 2.ed. rev. E atual. São Paulo: Saraiva, 2009.

CHRISTOPHER, M. Logística e gerenciamento da cadeia de suprimentos. São Paulo: Pioneira, 1999.

HARRISON, A.; HOEK, R. V. Estratégia e Gerenciamento de Logística. Tradução de Bazán Tecnologia e Linguística. São Paulo - Futura, 2003.

PORTER, Michael e TEISBERG, E. Repensando a Saúde: Estratégias para melhorar a qualidade e reduzir custos. Porto Alegre. Bookman, 2007.

ROCHA, Paulo Cesar Alves. Logística \& Aduana. 3. ed. São Paulo: Aduaneiras, 2007.

SAATY, T. L. Decision Makers for Leaders. New York, USA: McGraw-Hill, 1980

SIMCHI-LEVI, D.; KAMINSKY. Cadeia de suprimentos: projetos e gestão. Porto Alegre: Bookman, 2003. 